\title{
Flora das cangas da Serra dos Carajás, Pará, Brasil: Thuidiaceae
}

Flora of the canga of the Serra dos Carajás, Pará, Brazil: Thuidiaceae

Fúvio Rubens Oliveira-da-Silva ${ }^{1} \&$ Anna Luiza Ilkiu-Borges ${ }^{1,2}$

\begin{abstract}
Resumo
Este estudo reúne as espécies de Thuidiaceae registradas para as áreas de canga na Serra dos Carajás, no estado do Pará, incluindo descrição, ilustração e comentários morfológicos da espécie Pelekium scabrosulum, única registrada para a área de estudo.
\end{abstract}

Palavras-chave: Brioflora, FLONA Carajás, musgo, taxonomia.

\begin{abstract}
This study presents the species of Thuidiaceae recorded for the areas of canga in the Serra dos Carajás, Pará state, including description, illustration and morphological comments on Pelekium scabrosulum, the only species recorded in the study area.
\end{abstract}

Key words: Bryoflora, FLONA Carajás, mosses, taxonomy.

\section{Thuidiaceae}

Thuidiaceae Schimp. reúne musgos pleurocárpicos que estão representados por três gêneros e ca. de 30 espécies no Neotrópico (Gradstein et al. 2001). No Brasil, foram registrados dois gêneros e 16 espécies (Soares 2015). A família é caracterizada pela ramificação pinada (1 a 3 pinada), dimorfismo entre os filídios do ramo principal e ramos secundários, costa simples, células uni a pluripapilosas e presença de paráfilos no caulídio (Churchill \& Linares 1995; Buck 2003; Soares 2015). Foi registrada uma espécie de Pelekium Mitt. nas cangas da Serra dos Carajás.

\section{Pelekium Mitt.}

São reconhecidas oito espécies para o Brasil (Soares 2015). Os membros desse gênero encontramse principalmente em florestas tropicais sobre rocha, solo, madeira em decomposição e na base de árvores (Churchill \& Linares 1995; Gradstein et al. 2001). O gênero distingue-se pela ramificação 1-3 pinada, filídios com células uni a pluripapilosas e paráfilos simples ou pouco ramificados (Churchill \& Linares 1995; Soares 2015).
Pelekium scabrosulum (Mitt.) Touw, J. Hattori Bot. Lab. 90: 204. 2001.

Thuidium scabrosulum Mitt., J. Linn. Soc., Bot. 12: 575.1869.

Fig. 1a-i

Plantas verdes a marrom-avermelhadas com 3-6 cm de comprimento. Caulídio 2-pinados, paráfilos com 2-6(-8) células de comprimento, células quadradas a subquadradas, $6-12 \mu \mathrm{m}$, papilosas. Filídios do ramo principal encurvados quando secos, ovalado-deltóides, $0,4-0,6 \times 0,2-0,4 \mathrm{~mm}$, planos a côncavos, ápice longo-acuminado, margem crenulada, papilosa, costa simples, até $2 / 3$ do filídio. Células medianas do filídio retangulares a isodiaméticas, 7-20 × 5-7,5 $\mu \mathrm{m}$, pluripapilosas, 2-3(-4) papilas. Filídios dos ramos secundários e terciários encurvados quando secos, patentes quando úmidos, ovalados, $0,2-0,4 \times 0,1-0,2$ $\mathrm{mm}$, côncavos, ápice agudo a subagudo, margem crenulada, papilosa, costa simples, até $2 / 3$ do filídio. Células medianas do filídio subquadradas a isodiaméticas, 7-12,5 $\mu \mathrm{m}$, pluripapilosas, 2-4(-5) papilas. Filídios periqueciais ovaladolanceolados, margem sem cílios.

\footnotetext{
${ }^{1}$ Museu Paraense Emílio Goeldi, Av. Magalhães Barata 376, São Braz, 66040-170, Belém, PA, Brasil.

${ }^{2}$ Autor para correspondência: ilkiu-borges@museu-goeldi.br
} 
Material selecionado: Canaã dos Carajás, S11B, 6²1'19,1'S, 50²3'27,4”W, 29.IV.2015, A.L. IlkiuBorges et al. 3518 (MG). Parauapebas, N2, 31.III.1993, C.S. Rosário \& J.S. Ramos 818 (MG).

Moraes \& Lisboa (2006) registraram duas amostras de Pelekium schistocalyx (Müll. Hal.) Touw para canga na Serra dos Carajás. Entretanto, apenas uma amostra de canga foi localizada no herbário MG e esta corresponde a P. scabrosulum. Pelekium scabrosulum é reconhecido pelos filídios periqueciais com margem apresentando poucos cílios (Buck 2003), mas na amostra de Carajás, esses filídios não apresentaram cilíos, corroborando com o que foi observado por Soares
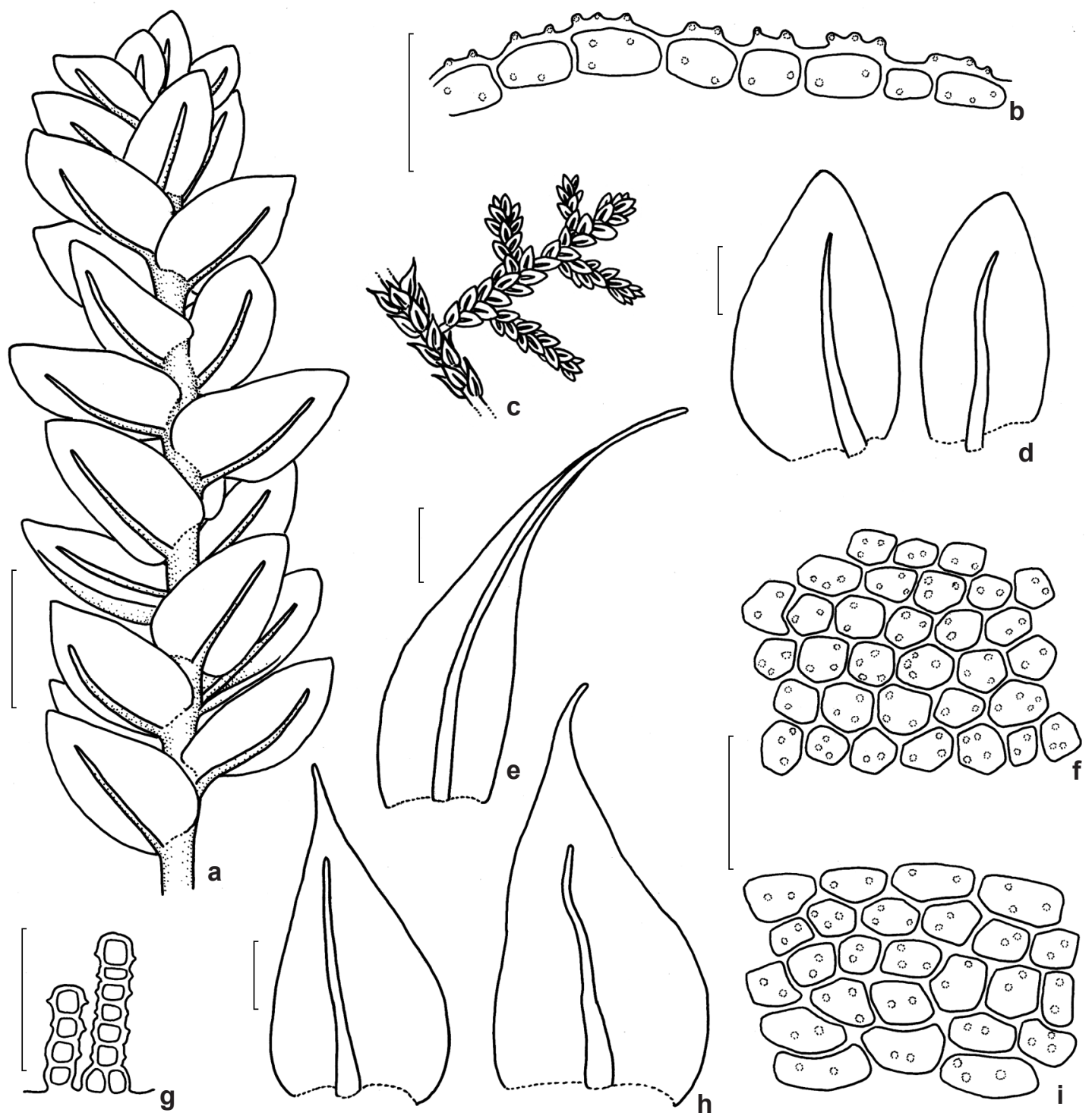

Figura 1 -a-i. Pelekium scabrosulum - a. ramo secundário; b. margem de um filídio, c. esquema do hábito; d. filídios de ramos secundário e terciário; e. filídio periquecial; f. células mediadas do filídio do ramo secundário e terciário; g. paráfilos; h. filídios do ramo principal; i. Células mediadas do filídio do ramo principal. Barras: a, e = 250 $\mu \mathrm{m}$; d, $\mathrm{g}=100 \mu \mathrm{m} ; \mathrm{g}=50 \mu \mathrm{m} ; \mathrm{b}, \mathrm{f}, \mathrm{i}=25 \mu \mathrm{m}$.

Figure 1 - a-i. Pelekium scabrosulum - a. secondary branch; b. leaf margin; c. habit scheme; d. leaf of secondary and tertiary branches; e. perichaetial leaf; f. median cells of a leaf from secondary and tertiary branch; g. paraphyllia; h. leaf of primary branch; i. median cells of a leaf from primary branch. Bars: $\mathrm{a}, \mathrm{e}=250 \mu \mathrm{m} ; \mathrm{d}, \mathrm{g}=100 \mu \mathrm{m} ; \mathrm{g}=50 \mu \mathrm{m} ; \mathrm{b}, \mathrm{f}, \mathrm{i}=25 \mu \mathrm{m}$. 
(2015). Além disso, P. scabrosulum apresenta filídios dos ramos secundários laxos quando secos, deixando o caulídio visível, enquanto que $P$. schistocalyx apresenta filídios secundários imbricados quando secos, encobrindo a superfície do caulídio. Adicionalmente, $P$. schistocalyx apresenta muitos cílios nos filídios periqueciais.

Segundo Buck (2003) e Soares (2015) essa espécie cresce em locais secos ou úmidos, sobre solo, rochas e troncos vivos ou madeira em decomposição em ambientes mésicos e florestas, principalmente na região amazônica. $\mathrm{Na}$ Serra dos Carajás, essa espécie foi coletada sobre tronco em decomposição.

América Central e do Sul. No Brasil: AC, AL, AM, BA, DF, ES, GO, MA, MG, MS, MT, PA, PE, PR, RJ, RO, RR, RS e SP. Serra dos Carajás: Serra Norte: N2; Serra Sul: S11B.

\section{Agradecimentos}

Agradecemos ao Museu Paraense Emílio Goeldi e Instituto Tecnológico Vale, a infraestrutura e demais apoios fundamentais para o desenvolvimento deste trabalho, assim como à Dra. Ana Maria Giulietti Harley e ao Dr. Pedro Viana, coordenadores do projeto conveniado MPEG/ITV/FADESP (01205.000250/2014-10) e ao projeto aprovado pelo $\mathrm{CNPq}$ (processo 455505/2014-4), o financiamento; ao ICMBio, em especial ao biólogo Frederico Drumond Martins, a licença de coleta concedida e suporte nos trabalhos de campo; ao CNPq, a bolsa de Mestrado concedida ao primeiro autor e a bolsa de Produtividade em Pesquisa concedida à segunda autora.

\section{Referências}

Buck WR (2003) Guide to the plants of Central French Guiana. Part 3. Mosses. Memoirs of The New York Botanical Garden 76: 1-167.

Churchill SP \& Linares CEL (1995) Prodromus Bryologiae Novo-Granatensis: introduccion a la flora de Musgos de Colombia. Biblioteca José Jerónimo Triana 12: 1-924.

Gradstein SR, Churchill SP \& Salazar-Allen N (2001) Guide to the Bryophytes of Tropical America. Memoirs of the New York Botanical Garden 86: $1-577$.

Moraes ENR \& Lisboa RCL (2006) Musgos (Bryophyta) da Serra dos Carajás, estado do Pará, Brasil. Boletim do Museu Paraense Emílío Goeldi, série Ciências Naturais 1: 39-68.

Soares AER (2015) A Família Thuidiaceae Schimp. no Brasil, um estudo taxonômico, filogenético e morfológico. Tese de Doutorado (em Botânica). Universidade de Brasília, Brasília. 202p.

\section{Lista de exsicatas}

Ilkiu-Borges AL et al. 3517 (1.1), 3518 (1.1). Rosário CS \& Ramos J 818 (1.1). 
